\title{
Cholescintigraphy for Differentiation of True Duodenal Obstruction from Pseudo Obstruction
}

\author{
Paul Rodrigue, Pankaj Nepal, and Richard Assaker \\ Department of Radiology, St. Vincent's Medical Center, Bridgeport, Connecticut
}

Small-bowel obstruction is a fairly common cause of abdominal pain. Differentiating between true duodenal obstruction and pseudo obstruction is important given differing treatment strategies. Here, we present augmentation of a hepatobiliary scan with a small amount of oral liquids and delayed imaging to differentiate between these two entities.

Key Words: gastrointestinal; cholecystitis; cholescintigraphy; common bile duct obstruction; duodenal obstruction; malrotation

J Nucl Med Technol 2020; 48:344-345

DOI: $10.2967 /$ jnmt.120.246132

\section{W.}

e present the case of a 51-y-old woman with bilious vomiting and right-upper-quadrant abdominal pain. Hepatobiliary scanning showed lack of radiotracer transit to the small bowel, with mild reflux into the stomach. Giving the patient a small amount of water before obtaining delayed imaging was successful in excluding true duodenal obstruction secondary to variant anatomy such as malrotation.

\section{CASE REPORT}

A 51-y-old woman presented with upper abdominal pain, bilious vomiting, and possible gallbladder wall thickening on recent ultrasound. Abdominal CT (Fig. 1) performed during the same emergency room visit demonstrated a large calculus in the neck of the gallbladder, compressing the adjacent duodenum. Immediately after intravenous administration of $214.6 \mathrm{MBq}(5.8 \mathrm{mCi})$ of ${ }^{99 \mathrm{~m}} \mathrm{Tc}-$ mebrofenin $(2-$ [[2-(3-bromo-2,4,6-trimethylanilino)-2-oxoethyl]-(carboxymethyl) amino]acetic acid), the patient was imaged over 60 min (Fig. 2).

The images demonstrated normal uptake and excretion of radiotracer by the liver. Radiotracer was visualized within the gallbladder and common bile duct by $10 \mathrm{~min}$ after injection. At approximately $25 \mathrm{~min}$, incidental reflux into the stomach was visualized. No bowel activity distal to the

Received May 1, 2020; revision accepted May 27, 2020.

For correspondence or reprints contact: Paul Rodrigue, Department of Radiology, 2800 E. Main St., St. Vincent's Medical Center, Bridgeport, CT 06606.

E-mail: paulrodrigue02@gmail.com

Published online Jul. 24, 2020.

COPYRIGHT (c) 2020 by the Society of Nuclear Medicine and Molecular Imaging.
FIGURE 1. Abdominal CT performed earlier during same emergency room visit demonstrated large calculus in neck of gallbladder, compressing adjacent duodenum.

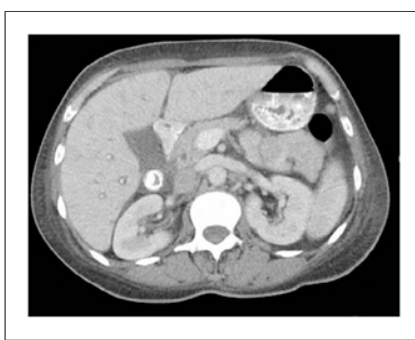

common bile duct was visualized within the first $60 \mathrm{~min}$ of imaging. The patient consumed approximately $118 \mathrm{~mL}$ ( $4 \mathrm{oz}$ ) of water orally at the conclusion of the initial imaging and was sent back to her hospital room. She returned $120 \mathrm{~min}$ later for delayed images $3 \mathrm{~h}$ after radiotracer injection. Delayed images in the anterior projection demonstrated radiotracer activity throughout the small bowel and into the ascending colon, excluding true small-bowel obstruction and showing that the gallstone in the neck of the gallbladder was responsible for this pseudo obstruction.

\section{DISCUSSION}

99m Tc-mebrofenin, an intravenously administered radiotracer, is commonly used to trace the production and flow of bile through the biliary system into the small intestine. For timely visualization of the gallbladder in adults, a minimum of $2 \mathrm{~h}$ and preferably $6 \mathrm{~h}$ of fasting is necessary before administration of the radiotracer. However, fasting for longer than $24 \mathrm{~h}$, such as is seen in morbidly ill hospitalized

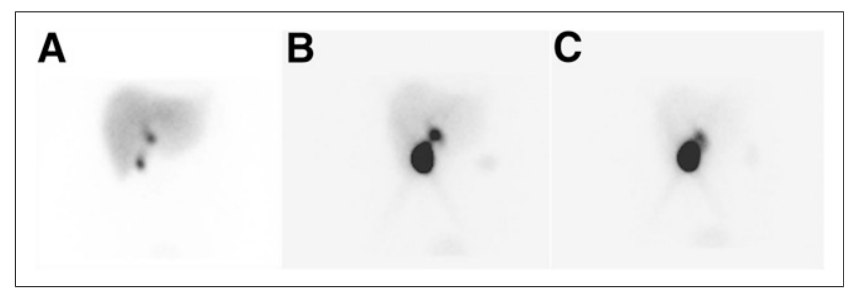

FIGURE 2. Hepatobiliary scintigraphy images after intravenous

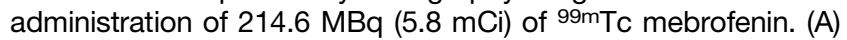
Normal uptake and excretion of radiotracer by liver, along with gallbladder and common bile duct, was visualized by $10 \mathrm{~min}$ after radiotracer injection. (B) At approximately $25 \mathrm{~min}$, incidental reflux into stomach was visualized. (C) No bowel activity distal to common bile duct was visualized at $60 \mathrm{~min}$ after radiotracer injection. 
patients, including those on total parenteral nutrition, can cause diagnostic pitfalls from nonvisualization of the gallbladder. In such cases, the patient may be pretreated with sincalide. Opioid medications also interfere with interpretive accuracy; such interference can be minimized by delaying the study for up to 4 half-lives of the medication. If needed, the opioid effect can be reversed with naloxone hydrochloride (1).

Nuclear studies using oral radiopharmaceuticals have previously been shown useful for imaging the transit of a food bolus through the gastrointestinal tract. In this instance, we offer cholescintigraphy as an alternative method for excluding true small-bowel obstruction. Numerous gastrointestinal pathologic conditions have long been described using cholescintigraphy (2,3). For patients with a history of bilious vomiting, hepatobiliary scanning may differentiate between acute cholecystitis, acute proximal gastrointestinal tract obstruction, and other undiagnosed conditions, such as malrotation $(4,5)$. After consultation with the radiology department, the decision was made to order a hepatobiliary ${ }^{99 \mathrm{~m}} \mathrm{Tc}-$ mebrofenin scan, which would offer a high sensitivity and specificity for evaluation of both these conditions $(3,6)$. Giving the patient a small amount of water orally may help to differentiate between true upper

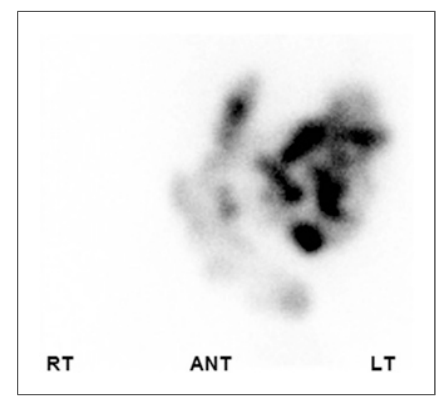

FIGURE 3. Delayed hepatobiliary scintigraphy image at $3 \mathrm{~h}$ after initial injection of radiotracer demonstrated transit of radiotracer throughout small bowel and into proximal colon. gastrointestinal obstruction or pseudo obstruction, as was true in this case. Delayed imaging at $3 \mathrm{~h}$ (Fig.3) after initial injection of the radiotracer demonstrated transit of radiotracer throughout the small bowel and into the proximal colon. Subsequently, the patient was taken to the operating room for laparoscopic cholecystectomy.

\section{CONCLUSION}

Augmentation of a nuclear hepatobiliary scan with a small amount of oral liquids and delayed imaging may be helpful in differentiating between true duodenal obstruction and pseudo obstruction.

\section{DISCLOSURE}

No potential conflict of interest relevant to this article was reported.

\section{ACKNOWLEDGMENT}

We acknowledge our patients, the great source of learning.

\section{REFERENCES}

1. Tulchinsky M, Ciak BW, Delbeke D, et al. SNM practice guideline for hepatobiliary scintigraphy 4.0. J Nucl Med Technol. 2010;38:210-218.

2. Fisher RS, Malmud LS. Scintigraphic techniques for the study of gastrointestinal motor function. Adv Intern Med. 1986;31:395-418.

3. Chandramouly BS, Burgess CK, Vaccaro RM. Diagnostic significance of unusual small intestinal pattern on technetium-99m DISIDA hepatobiliary imaging studies. Clin Nucl Med. 1987;12:852-856.

4. Weissmann HS, Sugarman LA, Frank MS, Freeman LM. Serendipity in technetium-99m dimethyl iminodiacetic acid cholescintigraphy: diagnosis of nonbiliary disorders in suspected acute cholecystitis. Radiology. 1980;135:449-454.

5. Fakhri AA, Hussain A, Taiyebi A, Fakhri AF. Duodenal obstruction on ${ }^{99 \mathrm{~m}}$ TcDISIDA cholescintigraphy: a noninvasive approach to bowel obstruction diagnosis. J Nucl Med Technol. 2016;44:265-266.

6. Ziessman HA. Hepatobiliary scintigraphy in 2014. J Nucl Med. 2014;55:967-975. 